\title{
An Exploratory Study on the Impact of an Organizational Performance through Lean Production Practices: A Case Study
}

\author{
Juthamas Choomlucksana ${ }^{l}$ and SeJoon Park ${ }^{2}$ \\ ${ }^{1}$ Department of Materials Handling and Logistics Engineering, \\ King Mongkut's University of Technology North Bangkok, \\ 1518, Pracharat 1 Rd., Wongsawang, Bangsue, Bangkok, 10800, Thailand. \\ ${ }^{2}$ Department of Industrial and Management Engineering, Myongji University, \\ 116, Myongji-Ro., Cheoin-Gu, Yongin-Si, Gyeonggi-Do, 448-728, Korea.
}

\begin{abstract}
Due to globalization, the world has become smaller and smaller with highly intense business competition. Thus, any organization, places more emphasis on looking for ways to survive based on reducing overall costs without decreasing product quality. Hence, identifying inefficient activities are becoming a core way to help manufactures decreasing in the operating costs while gaining a competitive advantage. However, few studies are concerned about searching for root causes of problems that are main obstacles for production improvement. Therefore, the purpose of this study is to explore on the impact of production performance and find a root cause for non-value-added activities through lean production and other quality tools application in a set of companies via a case study of SMEs. In short, bottleneck areas were identified for each company, and the problems were removed through increasing the processing time at those areas. The findings shows that motion and process wastes, compared to other wastes, are the main impacts for obstacles in production performance caused by poor workplace organization and lack of standardized work. The biggest barrier to lean production implementation is decentralization and changing the culture of workers, which requires the agreement of the top manager and involves of everyone in the entire SMEs.
\end{abstract}

Key words: Lean production, Non-value-added activity, Production performance, Waste, Quality tool

\section{INTRODUCTION}

These days, every single company, whether large or small, especially SMEs (Small and medium-sized enterprises), has a harder time surviving in the future because there are many other companies increasing competition all over the world and as production prices are market controlled. Therefore, companies are looking for ways to boost the company competitiveness and profits. In Thailand, SMEs play a major role, accounting for $98.5 \%$ of total business in the country [1]. Hence, SMEs are required to improve the quality for the entire process through reducing costs. In fact, reducing costs does not simply mean cutting employee work hours, laying off, or reducing the quality of input or output. Thus, each company needs to understand its production performance and find ways to identify non- value-added activity (NVA) in every step of production to solve the root cause and remain competitive in the face of unprecedented market changes.

Although several process improvement methodologies such as Six Sigma, TPS, and Total Quality Management, have been widely applied to existing processes within organizations, lean production also has successfully create work flow and has changed the workers' views of continuous improvement. Changing people's views of improvement and helping them understand which activities they should eliminate or change as core for sustainability and survival of business today.

Lean production, generally called lean, is focused on defining non-value-added activity, eliminating non- 
value-added activity, and increasing speed and flow through continuous improvement of processes, in order to decrease production system inefficiencies. Lean has been applied successfully for many decades that focused on understanding the main problems which effects on manufacture performance and cost through seven activities of waste. Although lean production was first used in an automotive industry, lean production principles and concepts can also apply in almost every environments such as healthcare and office. Womack and Jone [2] defined the term "Lean" in the book called "The Machine that Changed the
World", which caused lean to be known worldwide. What is a lean production? Lean production mainly focuses on identifying and eliminating non-valueadded activity's that impact on customer perception. Non-value-added activities, called waste or Muda (called in Japanese word) are any activities that do not increase value to operations and/or products from the customer perspective. Womack and Jone [2] defined waste as "any activity that does not create value as defined by the ultimate customer." Wastes present in manufacturing operations can be classified into seven types as shown in table 1 .

Table 1: Summarizes each forms of lean waste

\begin{tabular}{|l|l|}
\hline Lean Waste & Description \\
\hline Overproduction & $\begin{array}{l}\text { This occurs when a product is produced more than customers needed or before customers } \\
\text { wanted it. }\end{array}$ \\
\hline $\begin{array}{l}\text { Unnecessary } \\
\text { Inventory }\end{array}$ & $\begin{array}{l}\text { This occurs when all inventories (raw materials, unfinished manufacturing or parts) is } \\
\text { produced or stored in excess of real customer requirements. As a reason, all parts or goods are } \\
\text { spread all over the workplace, inventory, or warehouse, which requires extra handling and } \\
\text { space. }\end{array}$ \\
\hline $\begin{array}{l}\text { Unnecessary } \\
\text { Transportation }\end{array}$ & $\begin{array}{l}\text { This occurs when materials or information are unnecessarily moved around the production } \\
\text { process or from one place to another that is not required to complete the product or that does } \\
\text { not contribute to the product's value. }\end{array}$ \\
\hline Unnecessary Waiting & $\begin{array}{l}\text { This occurs when waiting for parts/services, machines, or other colleagues to finish during a } \\
\text { previous or current step in the process. Workers will not do anything until the previous work } \\
\text { arrives. This results in unnecessary waiting, which increases the production cycle time without } \\
\text { adding value to the product because the next person in line, is overwhelmed, the machine broke } \\
\text { down, someone is waiting to check materials, or something has run out. }\end{array}$ \\
\hline Unnecessary Motion & $\begin{array}{l}\text { This occurs when operators or workers require extra steps or unnecessary walking/movement } \\
\text { without adding value to the product, service or process due to poor workspace layout, an } \\
\text { unprepared workplace, misplaced or lost items, forced reprocessing, or ergonomic concerns. }\end{array}$ \\
\hline Over processing & $\begin{array}{l}\text { This occurs when an employee performs any works more than is required, or employee does } \\
\text { multiple work steps of the same task. }\end{array}$ \\
\hline Defects & $\begin{array}{l}\text { This occurs when producing products, services, or defective parts that do not conform to } \\
\text { customer specifications or expectations which requires additional time, resources, and money } \\
\text { to fix. }\end{array}$ \\
\hline
\end{tabular}

Lean production consists of a set of techniques and tools that apply to improvement, including value stream mapping (VSM), 5S (five workplace organizational concepts, all of which start with the letter "S"), Kaizen, visual control, and others. The VSM is the most common and popular lean tool that has been used to illustrate production processes visually and identify waste through overall production process. The VSM can help to indicate both information and material flow while expressing value adding (VA) and non-value-added (NVA) activities from the beginning of the process until the customer receives the products or services. By taking together among of these lean techniques and tools can lead companies to improve organizational performance efficiency. In general, workers implement lean production follow five fundamental principles of lean thinking, which consists of five phases as follows:

1) Specify Value: Ensuring products are provided to meet customers actually desire.

2) Map the Value Stream: Identifying all the steps in the value stream and find ways to eliminate waste as possible.

3) Create Flow: Ensuring the process are flow smoothly in a sequence. 
4) Establish Pull: Producing products or services when the customer want or pulling products or services from the next upstream activity.

5) Seek Perfection: Making organization being perfect solution and keeping continuous improvements as become an organization culture.

\section{RESEARCH BACKGROUND}

\section{Bottleneck}

A bottleneck in the production process is mainly limited the capacity of the whole chain and also occur frequently causing cumulatively significant of long-term problems, supply overstock, and decreasing productivity. Examples of bottleneck are long wait and backlogged work, which may also increase stress levels. Additionally, the maximum cycle time in the product line determines the bottleneck process. A bottleneck can be classified into short-term and long-term bottlenecks. Short-term bottleneck may cause of out of raw materials, lack of manpower, and machine temporarily unavailable. Beside, long-term bottleneck occurs which impact on creating a product queue and longer overall cycle time. Although short-term bottlenecks are temporary and are not a big problem compared to longterm bottlenecks, short-term bottleneck can result in long-term bottlenecks which continue to be a particular obstacle to smooth processes, improved productivity, and decreased cycle time. Even though, bottlenecks can be solved by defining the areas where accumulation occurs and adjusting the production level either additional machine or increasing the labor in the critical area, a drawback to improving the critical areas may be reducing production capabilities in others.

\section{Benefits of Lean Production Application}

Regarding the fact that a bottleneck can slow down the entire production process, lean production, also can called lean, can help to boost production capacity by reducing or eliminating the downtime of operations in which there is a bottleneck by eliminate non-valueadded activities and/or decrease necessary non-valueadded activities. There is no doubt that lean production can be applied in any industrial sectors. Many studies have proved numerous benefits gained from applying lean techniques and tools. For example, lean production is seen as a successful improvement methodology [3-5]. Additionally, in a study by Womack and Jone [2], the concepts of VSM were applied to an Auto-part Company in the ABC region of Sao Paulo. VSM was used to identify Value added (VA) vs. NVA during the assembly line of clutch discs. After applying the VSM, approximately $7 \%$ of total production time was reduced and also about $10 \%$ the use of work position was increased. Similarly, Roya,, Moradi and Toomari [6], applied lean to reduce the time spent on scheduling process and eliminate non-value adding activities in an outpatient sports medicine clinic with positive results. The results showed that the use of lean helped the hospital improve the patient scheduling process. Approximately $76 \%$ of patients were scheduled with only one call; averaging 2.5 minutes per call after 14 months of apply lean techniques and tools.

Therefore, the research begin with the exploration of performance improvement in a set of SMEs as a case study on production performance in two industrial areas, the sheet stamping metal and food manufacturing industries in Thailand through lean production application. The first step was to identify the bottleneck areas of each company by comparing the difference between the cycle time and the takt time of each company. The bottleneck areas of each company were investigated and measured as critical points. The next step was to find the main root cause of accumulation process delay and poor performance perhaps lean production waste, which is the main obstacle for decreasing the companies' productivity. Finally, the results of lean production and other quality tools were investigated and applied, first by collecting the actual time taken to complete, each stage's tasks and then by developing a current VSM, identifying the operational bottleneck areas, and detecting the lean activities waste at the problem areas to increase production flow and speed.

\section{RESEARCH METHODOLOGY}

In order to achieve the goal, eight SMEs, four from the sheet stamping metal and other from food sectors, were selected. These eight SMEs were purposively selected due to having no experience with lean production application. The sheet stamping method industry mostly produces part components for domestic companies in Thailand, whereas, the list of food companies encompasses Milk-Tablets, Fruit drink, noodle, and Sweet chili sauce. The sheet stamping metal companies are typically divided into six processes, shearing (cutting part from a large sheet), punching, bending, stamping, deburring for cleaning and coating parts, and packing. On the other hand, food manufacturing generally consists of five phases including raw material preparation (cleaning and washing), mixing, boiling, testing, and packing.

Before collecting the data, workers involved in the operational bottleneck areas were included as a team project. Both lean production and quality tools were used prior to gather data needed and improve the productivity in the problem areas. Data were collected internally in eight companies through observation and interviews that addressed time management and identification of the main problems in each company. A pre-audit found that each SME production performance was slow and there were lots of idle time during 
production. Data were collected on the total amount of time taken to complete an order from the beginning station, raw materials preparation, to final station, finished goods. A current map was drawn using the VSM of each company to document how things actually operated on during production including information flow, material flow, production lead time and production processing time. The study focused on any activities that created an obstacle to production flow within the production process. Takt time of each SME was calculated. Takt time refers to the rate at which customer are buying products or services. Takt time is German word Takzeit, mean rhythm of music. The calculation for Takt time and cycle time are as follows:

$$
\text { Takt time }=\frac{\text { Net Time Available for Production }}{\text { Customer's Daily Demand }}
$$

The cycle time of each station for the entire process was also investigated and measured. The cycle time can calculate and measure by adding machine time and man time for each stage together. As the bottlenecks can slow down, block, or stop the production line. The main focus of this project was identifying bottleneck stages and areas in the production process of each company before making improvement decisions. The bottleneck stages of all companies were identified for future improvement. Generally, the longest cycle time for each company's total time among the different stages resulted in bottlenecks, and was essential for identifying processing delays. Thus, the bottleneck processes were determined by the maximum cycle time across the line. From Table 2 and 3, the bottleneck stages of each company were identified and classified following cycle time, number of steps used to complete the task, type of waste, and other problems of each company that found during investigation.

\begin{tabular}{|c|c|c|c|c|}
\hline COMPANY & $\begin{array}{l}\text { BOTTLENECK STAGE } \\
\text { (PROCESS) }\end{array}$ & CYCLE TIME BEFORE IMPROVEMENT & NUMBER OF STEPS USED & WASTE \\
\hline \multirow[t]{2}{*}{1} & Deburring & $6,582 \mathrm{sec} / \mathrm{batch}$ & 1,086 steps & Motion \\
\hline & Other problems found. & \multicolumn{3}{|c|}{$\begin{array}{l}\text { - Production delays because of poor layout (distances between machine and inventory) } \\
\text { - Overtime, about three hours per day } \\
\text { - Material kept in disorder }\end{array}$} \\
\hline \multirow[t]{5}{*}{2} & Blanking \& Piercing & $28.2 \mathrm{sec} / \mathrm{piece}$ & 39 steps & Motion \\
\hline & Bending 1 & $14.70 \mathrm{sec} / \mathrm{piece}$ & 47 steps & Motion \\
\hline & Bending 2 & $27.43 \mathrm{sec} / \mathrm{piece}$ & 34 steps & Motion \\
\hline & Forming & $26.00 \mathrm{sec} / \mathrm{piece}$ & 32 steps & Motion \\
\hline & Other problems found. & \multicolumn{3}{|c|}{ - Workers took a long time to find parts because of non-specific work process areas. } \\
\hline \multirow[t]{3}{*}{3} & Stamping & $3,252.48 \mathrm{sec} / \mathrm{batch}$ & 23 steps & Motion \\
\hline & Packing & $625.00 \mathrm{sec} / \mathrm{batch}$ & 23 steps & Motion \\
\hline & Other problems found. & \multicolumn{3}{|c|}{$\begin{array}{l}\text { - Similar-looking parts (homogeneous appearances of part A and part B), causing } \\
\text { mix-ups of parts at the same package. }\end{array}$} \\
\hline \multirow[t]{2}{*}{4} & Stamping & $47.63 \mathrm{sec} / \mathrm{batch}$ & - & $\begin{array}{l}\text { Motion, Process, } \\
\text { and Defects }\end{array}$ \\
\hline & Other problems found & \multicolumn{3}{|l|}{ - Production delay cause of many parts } \\
\hline
\end{tabular}

Table 2 Summary Data found during First Audit: Sheet Metal Stamping Company

\begin{tabular}{|c|c|c|c|c|}
\hline COMPANY & $\begin{array}{l}\text { BOTTLENECK STAGE } \\
\text { (PROCESS) }\end{array}$ & $\begin{array}{l}\text { CYCLE TIME BEFORE } \\
\text { IMPROVEMENT }\end{array}$ & NUMBER OF STEPS USED & WASTE \\
\hline \multirow[t]{2}{*}{1} & Packing & $28.33 \mathrm{sec} / \mathrm{batch}$ & 9 steps & Motion \\
\hline & Other problems found. & \multicolumn{3}{|c|}{$\begin{array}{l}\text { - Company has a small facility. } \\
\text { - Machine running } 24 \text { hours a day, causing difficulty in maintaining machines. }\end{array}$} \\
\hline \multirow[t]{3}{*}{2} & Preparing & $900 \mathrm{sec} / \mathrm{batch}$ & 13 steps & Motion, process \\
\hline & Packing & $5,010 \mathrm{sec} / \mathrm{batch}$ & 12 steps & Motion \\
\hline & Other problems found. & \multicolumn{3}{|c|}{$\begin{array}{l}\text { - Raw materials are all heavy so operators need to handle heavy parts all the time } \\
\text { cause of fatigue and poor productivity during the day. }\end{array}$} \\
\hline \multirow[t]{2}{*}{3} & Packing & $21,777 \mathrm{~min} / \mathrm{batch}$ & 12 steps & $\begin{array}{l}\text { Motion, } \\
\text { Transportation, } \\
\text { and Defects }\end{array}$ \\
\hline & Note & \multicolumn{3}{|c|}{ - Machine running 24 hours a day and old machine. } \\
\hline \multirow[t]{2}{*}{4} & Packing & $2,160 \mathrm{~min} / \mathrm{batch}$ & 7 steps & Motion \\
\hline & Other problems found. & \multicolumn{3}{|c|}{$\begin{array}{l}\text { - Productions delay because of poor layout (Distance between machine and } \\
\text { inventory). }\end{array}$} \\
\hline
\end{tabular}

Table 3 Summary Data Found During First Audit: Food Company 
The appropriate of lean production concepts and also quality tools were employed depending on the type of waste encountered in each bottleneck stage during the production. Thus, several lean production techniques and tools such as 5S, Kaizen, Visual Control, and quality tools such as ECRS, flow process, and flow diagram, were considered and applied to analyze and improve the bottleneck stages of each company. The following lean production techniques and other basic quality tools were applied in order to improve the bottleneck stage for each SME production process.

- Value Stream Mapping (current and future), Flow process diagram, and Line balancing were used to help the SME's easily visualized process, recognizable bottleneck areas, and identified wastes. VSM allowed each company to identify and qualify the overall waste and time in each step of the production process and find ways to improve or solve the bottleneck. Future VSM was constructed after lean production and other quality tools were applied.

- The 5S were used to help the SMEs organize the workplace for maximum work condition efficiency by keeping materials and tools as close as possible to where the materials and tools are being used.

- Visual control was used to easily manage and recognize parts and elements at the workplace environment.

- Kaizen were applied as a way for all workplace improvement (See Figure 1, Figure 2, and Figure 3).

- Standardized work sheets were created. These sheet were used to help identify the actions required for each task in sequence and to review each step in the task, with the goal of finding a suitable way for continuous improvement.

Moreover, other applicable lean production techniques and tools such as Visual Control, Poka Yoke, Yamazumi chart, Why-why analysis. Additionally, several work Instructions and ECRS principles were applied.

\section{RESULTS and FINDINGS}

The significance of this study is to explore study on the impacts of the production performance regarding lean implementation and find a root cause of bottleneck stages regarding non-value-added activities and/or necessary non-value-added activities. The results showed that the waste, or relevant non-value-added activities in each SME case study, could be identified. The overall bottleneck performance was improved through lean production and also quality tools implementation. In figure 1 (from left to right), the coils were stored in an unorganized stack before lean production implementation. Workers wasted time finding and sorting parts. After implementing lean production, the coils became visible and reachable by using visual control and 5S. All materials are kept in place by separating them according to the customer company's alphabet.

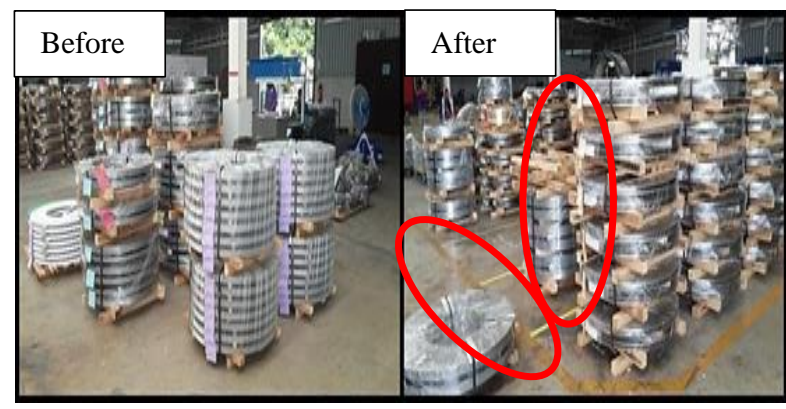

Fig 1 Examples of 5S for improving the workplace

From figure 2 (from the left to right and upper to lower), first, is shown about re-designed the materials handling of parts. Before, small fabric was used to start and stop parts for each batch (in the yellow cycle). After improvement, the machine was re-designed by adding digital counter to separate each batch when the number of parts is reached.

Second, before, the tray was lift up and off several times for cleaning scraps metal out of the machine. After improvement, new tray was redesigned by installing extra tray, so the scrap metal is automatically sent to the recycle bin.

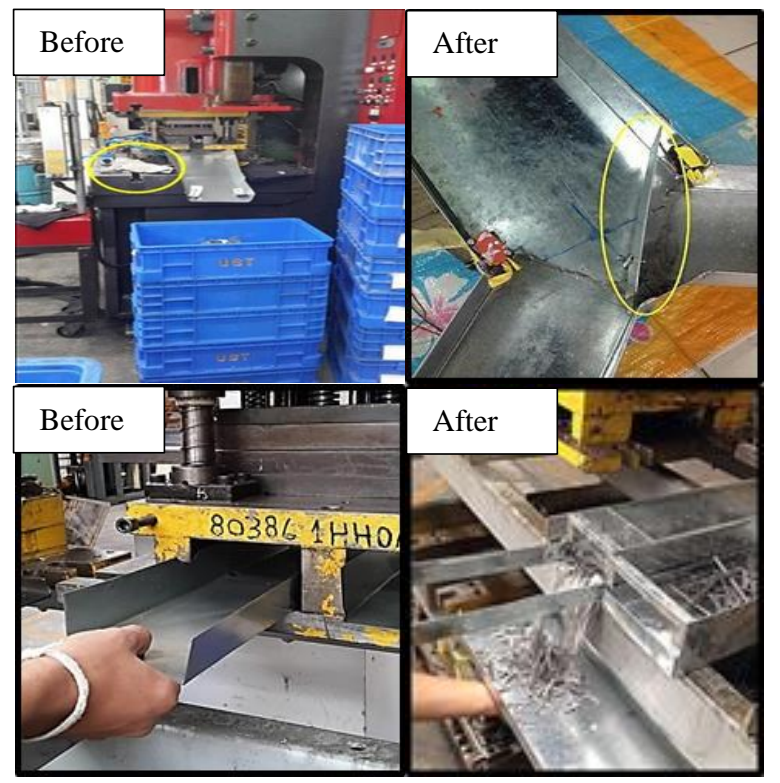

Fig 2 Examples of Kaizen activities for improving the workplace

Moreover, some improvement examples from the food manufacturing industries in Thailand are shown in figure 3. Why-why analyses were applied to find root causes for seven waste activities. As result, some procedures in bottleneck stages were changed. For example, forklifts are used instead of carrying by workers to reduce the number of raw material 
transportations during the washing and rice milling processes throughout the preparation stage.

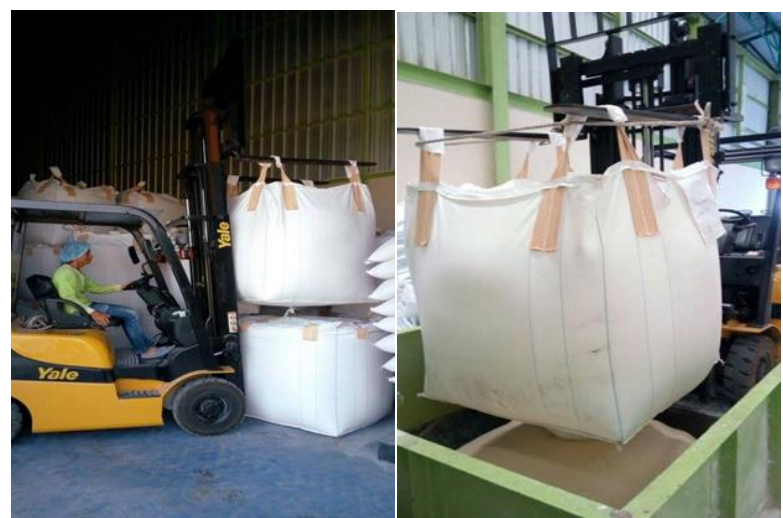

Fig 3 Examples of Waste eliminated for work improvement
Table 4 and table 5 below show the response on the effects of lean production techniques and other quality tools on each SME for improvement by monitoring the cycle time at bottleneck stage of each SME. Overall, there are clear indications that the production performance of each SME after implementation especially at the bottleneck stage has improved. The average cycle time at the bottleneck state of each SME has increased up to $50 \%$. Findings also identified that wastes of unnecessary motion and waste of over process or unnecessary movement compared to other wastes of lean production appear to be the most common type of wastes found in the SMEs' workplaces of the case study.

Table 4 Comparison of Cycle Time before and after Improvement: Sheet Stamping Metal Manufacturing

\begin{tabular}{|c|c|c|c|c|c|}
\hline \multirow{2}{*}{$\begin{array}{l}\text { SHEET } \\
\text { STAMPING }\end{array}$} & \multirow{2}{*}{$\begin{array}{l}\text { BOTTLENEC } \\
\text { K } \\
\text { STAGE }\end{array}$} & \multirow{2}{*}{$\begin{array}{l}\text { LEAN TOOLS/TECHNIQUE VS. } \\
\text { IMPROVEMENT TOOLS }\end{array}$} & \multicolumn{2}{|c|}{ CYCLE TIME (SEC) } & \multirow[b]{2}{*}{$\%$ IMPROVED } \\
\hline & & & BEFORE & AFTER & \\
\hline Company 1 & Deburring & $\begin{array}{l}\text { VSM, Visual Control, 5S, Kaizen, Poka- } \\
\text { Yoke }\end{array}$ & 6,582 & 2,468 & 62.5 \\
\hline \multirow[t]{4}{*}{ Company 2} & $\begin{array}{l}\text { Blaking \& } \\
\text { Piercing }\end{array}$ & \multirow[t]{4}{*}{$\begin{array}{l}\text { VSM, 5S (Shadow board), Kaizen, Poka- } \\
\text { Yoke, Flow Process chart/Flow Diagram }\end{array}$} & 28.2 & 14.1 & 50 \\
\hline & Bending1 & & 14.7 & 12.3 & 45.55 \\
\hline & Bending2 & & 27.43 & 13.8 & 49.7 \\
\hline & Forming1 & & 26 & 15 & 42.31 \\
\hline \multirow[t]{2}{*}{ Company3 } & Stamping1 & \multirow{2}{*}{$\begin{array}{l}\text { VSM, Visual Control (Color-coded areas } \\
\text { of basket), 5S, Kaizen, Poka-Yoke (Digital } \\
\text { Counter) }\end{array}$} & $3,252.48$ & 740.87 & 77.22 \\
\hline & Packing & & 625 & 0 & 100 \\
\hline Company4 & Stamping1 & $\begin{array}{l}\text { VSM, Kaizen, Work Instruction, Why-why } \\
\text { analysis, Yamazumi Chart }\end{array}$ & 47.63 & 0 & 100 \\
\hline
\end{tabular}

Table 5 Comparison of Cycle Time before and after Improvement: Food Manufacturing

\begin{tabular}{|c|c|c|c|c|c|}
\hline \multirow[b]{2}{*}{ FOOD } & \multirow[b]{2}{*}{$\begin{array}{l}\text { BOTTLENECK } \\
\text { STAGE }\end{array}$} & \multirow[b]{2}{*}{$\begin{array}{l}\text { LEAN TOOLS/TECHNIQUE VS. } \\
\text { IMPROVEMENT TOOLS }\end{array}$} & \multicolumn{2}{|c|}{ CYCLE TIME (SEC) } & \multirow[b]{2}{*}{$\%$ IMPROVED } \\
\hline & & & BEFORE & AFTER & \\
\hline Company 1 & Packing & $\begin{array}{l}\text { VSM, Kaizen (redesign ways to packing } \\
\text { Carton Board), Flow Process Chart/Flow } \\
\text { Diagram }\end{array}$ & 28.33 & 13.16 & 53.55 \\
\hline \multirow[t]{2}{*}{ Company 2} & Preparing & \multirow{2}{*}{$\begin{array}{l}\text { VSM, Kaizen,Flow Process Chart/Flow } \\
\text { Diagram, ECRS, Why-why analysis, } \\
\text { Multitaking techniques }\end{array}$} & 900 & 300 & 66.67 \\
\hline & Packing & & 5,010 & 2,220 & 55.68 \\
\hline Company3 & Packing & $\begin{array}{l}\text { VSM, Kaizen, Flow Process Chart/Flow } \\
\text { Diagram, ECRS, Cause and Effects } \\
\text { Diagram }\end{array}$ & 21,777 & 10,940 & 49.76 \\
\hline Company4 & Packing & VSM, 5W1H, ECRS & 2,160 & 1,500 & 30.56 \\
\hline
\end{tabular}

In short, waste or unnecessary motion and overprocessing were determined to have a high impact on goals for production performance. Unnecessary motion waste is the main reason for obstacles in SME production performance and is the root cause of bottlenecks through production process, due to poor workspace layout and lack of standardized work. The results found that most workers performed tasks based 


\section{Juthamas Choomlucksana / Journal of Engineering and Science Research, 2(2) 2018, Pages: 09-16}

on routine and not by following best practices or instruction. Workers spent more time waiting for, and searching for, parts and/or tools, which decreases value. Moreover, the study found that workers were trained when they were hired and performed their tasks by role at the beginning of job start; they could not recognize which tasks were value-added or non-value-added activities. In fact, the unnecessary processes found in this study are common issues; they are mainly caused by redundant steps. Workers were required to follow their supervisors' orders and were not allowed to make any decisions on their own or not involved in participate in brainstorming sessions or morning meetings. On the other hand, lean production concepts give everyone a chance to offer ideas, which creates the conditions for continuous improvement.

\section{CONCLUSIONS}

Typically, most companies, (especially, SMEs) are forced to find suitable ways to enhance cost-cutting through performance improvement. In first part of this study has focused on explaining the critical root causes of bottleneck stages and non-value-added activities for eight SMEs, which cause longer cycle times or smaller process rates through the production process. Identifying activities that are not provided value through the system is the main discussion for the project team. The results of this research study came from a real case study of eight SMEs in Thailand, the sheet stamping metal and food sectors. Through this research study, the critical areas, bottleneck stage, in each SME were identified by using current VSM, line balancing techniques and quality tools. VSM helps to identify seven waste activities, which is the first step in lean production in order to support production flow via SME case study.

Therefore, it is quite difficult to apply lean production and quality tools across the production process during the working day. As the reason, only the critical bottleneck areas were investigated and analyzed. Times including total processing time, cycle time, and takt time were calculated and identified to enhance the companies' knowledge of their weak points. The results of these analyses indicated that although there are different featured industries, non-value-added activities were the main root cause of the problems that had the highest impact on production performance for all companies. Moreover, when these problems were addressed the results were a reduction in required more manpower than they really needed at the bottleneck stage. Overall, the results show that workers are successful in an identifying and removing manufacturing waste from the bottleneck stage during the production process by using lean production and quality concepts.
In short, lean production and other quality tools were proved to enhance companies identify root cause and eliminate non-value-added activities, as the reason, other companies which has related process could apply these techniques and tools for productivity improvement effectiveness and efficiency. Moreover, the findings show that workers' lack of knowledge and skills are not the main cause of poor production performance; rather, increased demand and limited space are the main causes of waste, requiring a redesigned plant layout. Due to, workers' lack of engagement at work and follow the supervisors' orders without question are the main factors in a lack of continuous improvement, which in turn is the cause of both unnecessary work and unnecessary processes.

In conclusion, lean production is not a simple method that everyone can apply directly through processes; everyone at the company must be involved and clearly understood the principle of lean production before making decision to implement lean production. Additional, all workers must have the discipline to follow the standard procedures and must also have the power to suggest improvement to those procedures. The most critical success factors for lean production implementation are organization, workplace culture, and involvement of every worker in the production improvement process. As lean concepts appear to be a culture side by changing the ways of working and habits to see, identify, and eliminate non-value-added activities. Additionally, some limitations have been found in this research study as 1) the lack of lean production knowledge from employees; 2) lack of top and/or senior manager involved and supported; 3 ) the lack of understanding lean production concepts. Due to lean production is a concept that holds the idea of continuous improvement, lean workers must acquire the necessary knowledge and skill of lean concepts and principles, and/or other quality tools in order to apply an appropriate tools and techniques for particular problem areas. Besides, the workers think that working on the kaizen activities make extra work which means increasing hours spent away from the original work. Moreover, cultural, technical, organizational, and economic factors should be considered as various barriers to lean production implementation [7].

\section{ACKNOWLEDGMENTS}

The authors acknowledge the financial support from King Mongkut's University of Technology North Bangkok (KMUTNB), Bangkok, Thailand. 


\section{REFERENCES}

[1] ADB. 2014. Asia SME Monitor 2013. Manila: ADB.

[2] James, W.P., Jones, D. T., and Roos, D. 1991.The Machine that Changed the World: The Story of Lean Production, $1^{\text {st }}$ Harper Perennial Ed., New York.

[3] David. C.. Read. D.. Read. Mukheriee. P. and Cooke. M. 2011. Imnroving the aualitv of Emergencv Department care bv removing waste using Lean Value Stream manning. International Journal of Clinical Leadership 17(1), 25-30.

[4] Evgeniva. D.. and Gavrikova. N. 2016. Exnerience in annlving lean production concents in the service sector,In SHS Web of Conferences, 28.
[5] Farhana. F. 2009. An investigation of manufacturing nerformance imnrovement through lean production: A studv on Bangladeshi garment firms. International Journal of Business and Management 4(9), 1-1-11.

[6] Rova. D.. Moradi. R.. and Toomari. U. 2012. Barriers to imnlementation of lean accounting in manufacturing comnanies. International Journal of Business and Commerce1 9, 38-51.

[7] Mohamad. A.N.. Dhakal. H.. and Bennett. N. 2012. The role of culture and leadershin in lean transformation: a review and assessment model. International Journal of Lean Thinking 3 1,119-138. 